\title{
A circulação de um modelo verde no Brasil: a Biblioteca Parque Villa-Lobos
}

\author{
Cleide Elis da Cruz Raulino* \\ Roberta Barros Meira*
}

Artículo recibido:

13 de octubre de 2020

Artículo aceptado:

1 de diciembre de 2020

Artículo de investigación

\section{Resumo}

Este artigo apresenta um estudo de caso da Biblioteca Parque Villa-Lobos (BVL), localizada em São Paulo, Brasil. A BVL é integrante do Sistema Estadual de Bibliotecas Públicas de São Paulo (SisEB) e foi idealizada para tornar-se um modelo diferenciado, em que as pessoas, suas necessidades e seus interesses estão no centro da atenção e cujos recursos, livros, espaços e atividades culturais buscam satisfazer a seus requisitos de acesso à cultura e à informação. $\mathrm{O}$ artigo teve como objetivos pensar os avanços do modelo de bibliotecas parque, ao ser comparado o modelo ao de biblioteca pública tradicional do Brasil, analisar de que forma a sustentabilidade e a questão das bibliotecas verdes se

* Universidade da Região de Joinville (Univille). Programa de Pós-Graduação em Patrimônio Cultural e Sociedade, Brasil_lisraulino@gmail.com rbmeira@gmail.com

INVESTIGACIÓN BIBLIOTECOLÓGICA, vol. 35, núm. 88, julio/septiembre, 2021, México, ISSN: 2448-8321 pp. 13-28 
configuram no conceito parque na BVL e verificar os principais fatores que impactam em sua aplicabilidade e refletem em suas práticas. Ademais, busca expor uma reflexão crítica sobre os 17 objetivos de desenvolvimento sustentável da Agenda 2030, em consonância com os programas e serviços desenvolvidos ou em desenvolvimento, divulgados pelo site institucional da biblioteca.

Palavras-chave: Bibliotecas Públicas Brasileiras; Biblioteca Parque Villa-Lobos; Bibliotecas Verdes; Sustentabilidade

La circulación de un modelo verde en Brasil: la Biblioteca Parque Villa-Lobos

Cleide Elis da Cruz Raulino y Roberta Barros Meira

\section{RESUMEN}

Este artículo presenta un estudio de caso de la Biblioteca Parque Villa-Lobos (BVL), ubicada en São Paulo, Brasil. La BVL es parte del Sistema Estatal de Bibliotecas Públicas de São Paulo (SisEB) y fue diseñada para convertirse en un modelo diferenciado, en el que las personas, sus necesidades e intereses están en el centro de atención y cuyos recursos, libros, espacios y las actividades culturales buscan satisfacer sus requerimientos de acceso a la cultura y la información. El artículo tuvo como objetivo reflexionar sobre los avances del modelo de bibliotecas-parque, al comparar el modelo con la biblioteca pública tradicional en Brasil; analizar cómo la sostenibilidad y el tema de las bibliotecas verdes se configuran en el concepto parque en la BVL y verificar las principales. factores que inciden en su aplicabilidad y se reflejan en sus prácticas. Además, busca exponer una reflexión crítica sobre los 17 objetivos de desarrollo sostenible de la Agenda 2030, en línea con los programas y servicios desarrollados o en desarrollo publicados en el sitio web institucional de la biblioteca.

Palabras clave: Bibliotecas Públicas Brasileñas; Biblioteca Parque Villa-Lobos; Bibliotecas Verdes; Sustentabilidad 
The circulation of a Green model in Brazil: Parque Villa-Lobos Library

Cleide Elis da Cruz Raulino and Roberta Barros Meira

\title{
Abstract
}

This article presents a case study of the Parque VillaLobos Library (BVL), located in São Paulo, Brazil. The BVL is a member of the State System of Public Libraries of São Paulo (SisEB). It was designed to become a differentiated model, in which people, their needs and interests are at the center of attention and in which all resources, books, spaces and cultural activities seek to satisfy their requirements to access culture and information. The document aims to think about the advances of the park library model in comparison to the traditional public library in Brazil, to analyze how sustainability and the issue of green libraries are configured in the park concept at the BVL, and to verify the main factors that impact in their applicability and reflect in their practices. In addition, it seeks to present a critical reflection on the 17 sustainable development goals for the Agenda 2030, in line with the programs and services developed or in development, published on the institutional website of the library.

Keywords: Brazilian Public Libraries; Parque VillaLobos Library; Green Libraries; Sustainability

\section{INTRODUÇÃO}

\begin{abstract}
A criação e a manutenção das bibliotecas públicas são atividades essenAciaispara o desenvolvimento cultural, intelectual e social de um país. A biblioteca pública brasileira vem ao longo dos anos sofrendo com a falta de investimentos, recursos e infraestrutura, e isso tem afetado e se refletido no panorama atual, comprometendo suas atividades. Percebe-se ainda a falta de conscientização e de prioridade por parte dos governantes em implantar soluções, seja por meio das políticas públicas, seja por investimentos, para que as bibliotecas públicas, de modo geral, avancem na conquista dos seus direitos e consigam ampliar seus serviços e melhorar sua qualidade.
\end{abstract}


Apontam Medeiros e Olinto (2016: 3) que o desenvolvimento das bibliotecas públicas no Brasil e na América Latina, em geral, se deve muito à atuação dos organismos internacionais, o que tem permitido a troca de experiência e o compartilhamento de dificuldades e de soluções. Vale ressaltar que a biblioteca pública requer, além das experiências, políticas públicas e planejamento, incluindo a participação da comunidade e o comprometimento daqueles que fazem parte da biblioteca e que procuram esse espaço democrático e comunitário.

As bibliotecas públicas precisam quebrar alguns paradigmas e avançar em favor da sua missão e do seu público. Medeiros e Olinto (2016: 3) destacam que, além das funções tradicionais, as novas funções, voltadas para o desenvolvimento do cidadão e da coletividade, tendem a contribuir na redução das desigualdades sociais e digitais. Aliás, as bibliotecas públicas têm, entre tantos desafios, a tarefa de incluir aqueles que foram marginalizados, excluídos e esquecidos pela sociedade, assegurando o direito e o acesso à tecnologia, à cultura e à informação.

Com todo o aporte associado às bibliotecas públicas, um dos maiores desafios, de acordo com Suaiden (2018: 147), é "construir usuários produtores de informação e não mais usuários dependentes da informação". Assim, a biblioteca torna-se um importante elo entre a informação e o cidadão, no sentido de oferecer suporte para criar subsídios, para que o sujeito se torne alguém mais consciente e mais crítico, tanto em relação aos seus direitos quanto aos seus deveres. Barilon, Caldas e Ferrazoli (2018:3) afirmam:

As bibliotecas públicas têm potencial para desempenhar importantes funções na sociedade, caracterizando-se enquanto uma instituição capaz de articular relações democráticas e proporcionar o desenvolvimento da comunidade através da difusão de valores culturais, algo que culminará com o alcance de uma sociedade mais justa e igualitária através do absoluto exercício da cidadania.

Nesse sentido, as funções atribuídas à biblioteca pública são fortemente de cunho social e podem contribuir especialmente com aqueles que, por algum motivo, não têm acesso à cultura, à informação ou à tecnologia. Por isso, aponta-se que as bibliotecas públicas são "instituições fundamentais para promoverem o desenvolvimento das regiões as quais estão inseridas, fomentando o desenvolvimento de indivíduos através das mais variadas atividades culturais" (Barilon, Caldas e Ferrazoli, 2018: 2).

Na busca de melhor qualidade de vida, segundo Lima e Silva (2017: 2), "parece-nos oportuno pensar na inclusão da sustentabilidade na agenda das bibliotecas, sendo necessária a adequação destas ao esforço por bem-estar 
presente e futuro". No entanto, mais do que atender a uma recomendação normativa, a sustentabilidade na pauta das bibliotecas públicas representa o compromisso e a responsabilidade social de atuar como protagonistas nesse contexto.

Nosso objeto de estudo, a Biblioteca Parque Villa-Lobos (BVL), é parte integrante do Sistema Estadual de Bibliotecas Públicas de São Paulo (SisEB), que engloba as bibliotecas públicas municipais e comunitárias, incluindo também a Biblioteca de São Paulo (SisEB, 2020). ${ }^{1}$ Assim, a BVL torna-se lócus privilegiado da pesquisa, por ser um novo modelo de biblioteca pública, para compreender de que forma a sustentabilidade e a questão das bibliotecas verdes se configuram no conceito parque.

Traçamos um breve panorama das bibliotecas públicas brasileiras na atualidade, seguido de um estudo da BVL e de como a sustentabilidade se configura, destacando as evidências coletadas por meio de pesquisa bibliográfica, documental e observação direta. Nas considerações finais, demonstramos os principais fatores que impactam na aplicabilidade da sustentabilidade na BVL e como a teoria reflete em suas práticas.

\section{BIBLIOTECAS PÚBLICAS BRASILEIRAS: UM BREVE PANORAMA}

O Sistema Nacional de Bibliotecas Públicas (SNBP) foi instituído em 1992 e desde então trabalha de maneira articulada com os sistemas estaduais, municipais e do Distrito Federal de bibliotecas públicas, com os objetivos de fortalecer suas ações e estimular o trabalho em rede e colaborativo (SNBP, 2020). O SNBP visa à ampliação e ao fortalecimento dos serviços, programas e ações de incentivo ao livro, à leitura e às bibliotecas. Por isso, considera-se que "a biblioteca pública é de extrema importância para uma sociedade; é um agente do qual provém a informação, sendo, assim, um meio de democratização da leitura e do conhecimento para um país" (Freitas e Silva, 2014: 126).

No Brasil, segundo dados do SNBP (2015), são 6.057 bibliotecas públicas municipais, distritais, estaduais e federais, nos 26 estados e no Distrito Federal. Ademais, a Pesquisa de Informações Básicas Municipais do Instituto Brasileiro de Geografia e Estatística (IBGE) permite levantar a existência, nos municípios, de diversos tipos de equipamentos culturais. Nesse caso, equipamentos tradicionais como bibliotecas, por exemplo, cresceram em presença

1 O Governo do Estado de São Paulo criou em 1984 o SisEB, que direciona suas ações para que todas as bibliotecas públicas priorizem a cultura, para formar cidadãos e estimular a relação com a comunidade do entorno por meio da leitura e do acesso à informação (SisEB, 2020). 
nos 5.570 municípios brasileiros até 2014, chegando a 97,1\% naquele ano, mas com decréscimo em 2018, para 87,7\% (IBGE, 2019: 148). Se diversos são os fatores que podem ter contribuído para a queda desses dados, sabe-se que eles influenciam e impactam diretamente na realidade brasileira, confirmando que o país não possui bibliotecas em número suficiente para atender à população. Para Freitas e Silva (2014: 127),

a biblioteca pública brasileira é diretamente influenciada por uma série de fatores que contribuem para o seu sucesso ou fracasso. Dentre eles, podemos citar o investimento em educação e cultura, políticas públicas governamentais e a atuação do profissional bibliotecário junto à comunidade. Entretanto, ao longo dos anos, alguns problemas persistem e afetam o desempenho da biblioteca demonstrando um cenário crítico.

Tal cenário afeta diretamente o desenvolvimento da biblioteca e reflete na comunidade que a utiliza. Reforçando a ideia, ainda que possa ser contraditória, Medeiros (2010: 39) defende que a biblioteca pública, "embora basilar para o desenvolvimento pessoal ou coletivo, ainda não ocupa um lugar claro nas políticas públicas e na sociedade brasileira”.

No entanto, entre as tradicionais e as novas funções, visando adaptar-se a essa nova demanda é preciso, além de garantir as políticas públicas, estreitar laços com a comunidade e voltar-se para o desenvolvimento cultural e social e assim caminhar um pouco mais para chegar ao ideal de biblioteca pública. Acredita-se que, adotando essa nova mentalidade e colocando em prática questões como o que e a quem ela está servindo, esse novo modelo de bibliotecas públicas que está sendo implantado no Brasil, que são as bibliotecas parque, faria um sentido maior e se tornaria um local "onde a cultura é vista no seu todo, como um produto instituído de conhecimento, de cidadania e de mediação social" (Silva, 2012:35).

Poucas experiências se destacam no Brasil por seguir esse novo modelo de biblioteca pública. As bibliotecas parque no Rio de Janeiro e em São Paulo são alguns exemplos, por possuírem estrutura diferenciada e horário de atendimento ampliado - funcionam nos fins de semana - e desenvolverem ainda uma série de programações e de atividades culturais e educacionais envolvendo a comunidade. Também se caracterizam por estarem instaladas nas comunidades, especialmente aquelas em áreas de risco e com alto índice de violência. Sobressaem na proximidade com as pessoas, promovendo o elo entre a cultura, a informação e o cidadão. 


\section{Um parque, uma biblioteca}

A área onde se encontra hoje o Parque Villa-Lobos, na cidade de São Paulo, já foi, no início da década de 1980, um local de descarte irregular de todo tipo de resíduo que o município produzia. Logo após as comemorações do centenário de nascimento do músico brasileiro Heitor Villa-Lobos, em 1988, algumas áreas ocupadas irregularmente foram desapropriadas e foi realizada a remoção do solo contaminado, para se implantar um parque que contemplasse lazer, cultura e esporte.

Ocupando uma área de $732 \mathrm{~m}^{2}$, o parque apresenta instalações para a prática esportiva, anfiteatro e biblioteca. Foi inaugurado em 1994, e de lá para cá foram realizadas muitas benfeitorias, proporcionando à população melhor integração com o meio ambiente.

O pavilhão de concreto, aço e vidro de $4.000 \mathrm{~m}^{2}$, que originalmente foi concebido para sediar a Secretaria de Estado do Meio Ambiente de São Paulo, sofreu algumas adequações e foi destinado à Secretaria de Cultura e Economia Criativa do Estado de São Paulo para abrigar a BVL, conforme demonstra a Figura 1. Assim, a BVL foi criada por meio do Decreto n. ${ }^{\circ}$ 59.777, de 21 de novembro de 2013, como equipamento cultural da área de bibliotecas e leitura e inaugurada em 2014.

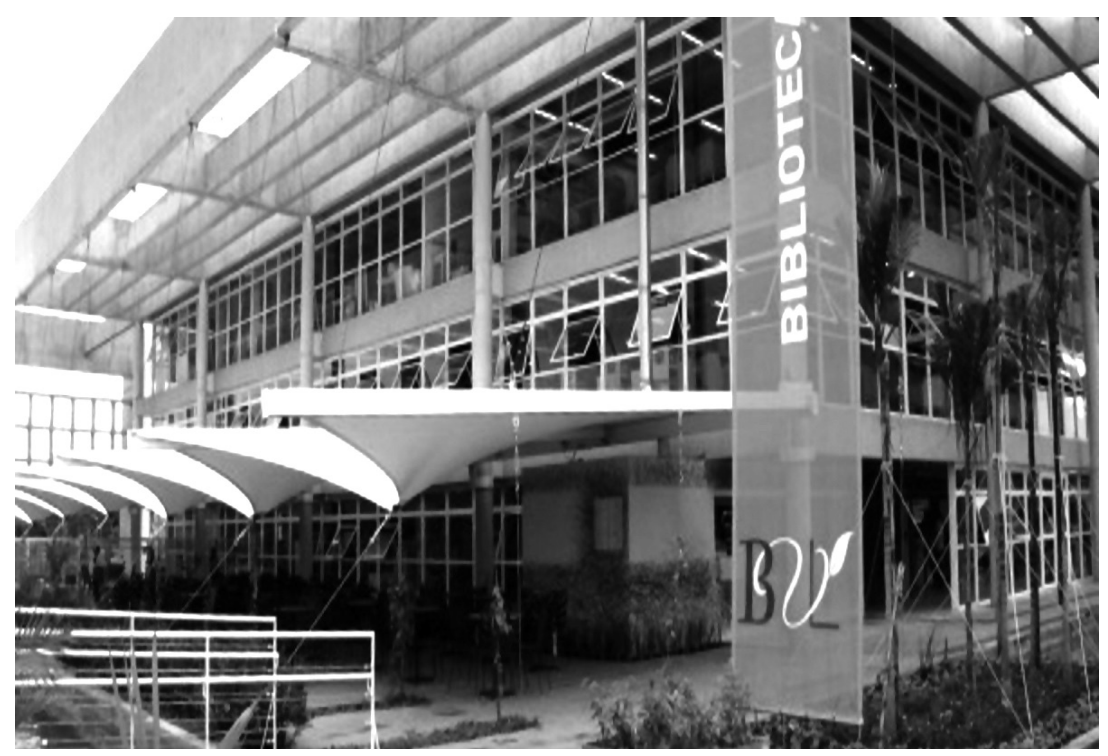

Figura 1. Biblioteca Parque Villa-Lobos, em São Paulo Fonte: BVL (2018) 
$\mathrm{Na}$ área central da biblioteca (Figura 2), o destaque fica por conta de uma estrutura arquitetônica semitransparente, que filtra a luz solar direta, e sob ela uma oca de madeira em grande escala compõe, com o piso de tatame, almofadas e pufes coloridos, um espaço para descontração e contação de histórias.

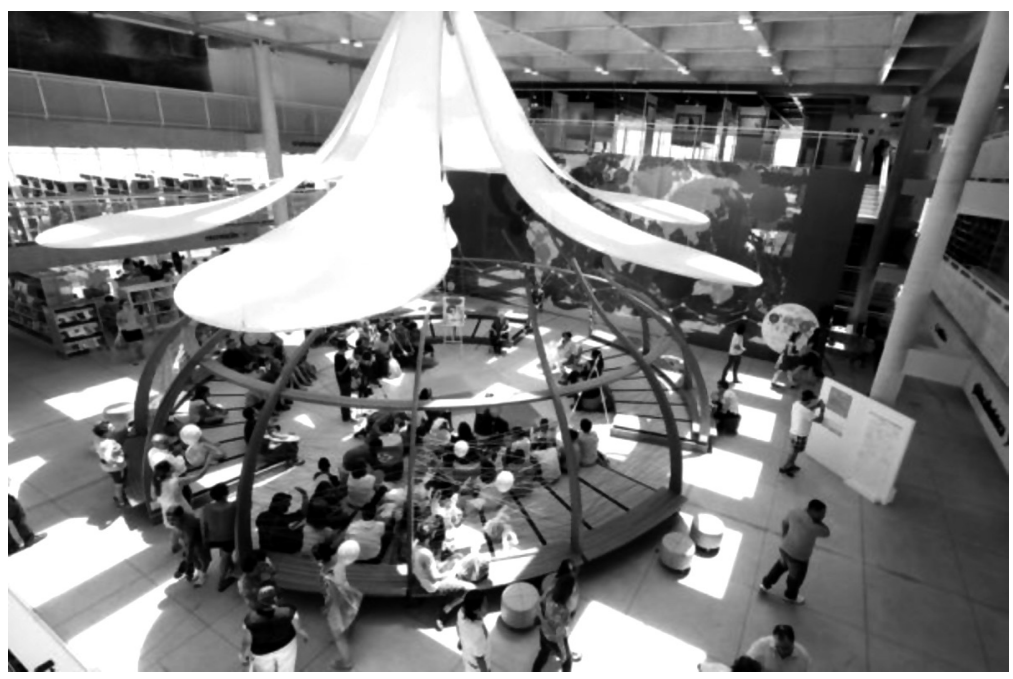

Figura 2. Área central da Biblioteca Parque Villa-Lobos, em São Paulo Fonte: BVL (2018)

A gestão da BVL está a cargo da Associação Paulista de Bibliotecas e Leitura (SP Leituras), que é uma organização social sem fins lucrativos criada em maio de 2010. A SP Leituras mantém contrato de gestão com a Secretaria da Cultura do Estado de São Paulo desde abril de 2011, para gerenciamento e desenvolvimento da BVL, bem como de ações e programas (SisEB, 2020).

A BVL conta com salas de criatividade, sala de jogos eletrônicos, ludoteca, espaço para os visitantes lerem com tranquilidade, computadores com acesso à internet e deck com vista para o parque. Dispõe de estrutura tecnológica para a comunidade e equipamentos voltados para a acessibilidade e inclusão. Além de contar com um acervo bastante atrativo, oferece uma programação bastante diversificada de interesse de vários públicos e tem como proposta trabalhar a inclusão social por meio da leitura. 


\section{Sustentabilidade na Biblioteca Parque Villa-Lobos}

As bibliotecas públicas têm papel importante, ao se tornarem grandes centros de disseminação de informação e contribuírem com as novas demandas da sociedade. Diante dos desafios e das mudanças no cenário mundial com relação às práticas sustentáveis, mediante a Agenda 2030, a qual assumiu compromisso com os 17 objetivos de desenvolvimento sustentável (ODS) e suas metas, as bibliotecas estão buscando se articular e colocar em prática as ações da Agenda. Tanto no Brasil quanto em outros países, o aumento populacional e da urbanização e o uso irracional dos recursos naturais têm se apresentado como desafios. "Ao levar essa investigação de práticas de sustentabilidade para o âmbito das bibliotecas, percebe-se que é necessário pensar em ações efetivas para que estes espaços possam colaborar com um desenvolvimento sustentável" (Spudeit e Prado, 2017: 140).

Acompanhar as transformações pautadas em manifestos, legislações e documentos norteadores auxilia as bibliotecas públicas a explorar o potencial do que melhor elas podem propiciar aos cidadãos e de como podem promover o conceito de sustentabilidade.

As bibliotecas públicas, por serem instituições mantidas pelo Estado (Município, Estado e Federação), devem ser as primeiras a incorporarem a construção sustentável, critérios e princípios de economia de recursos naturais, minimizar o impacto ambiental, gerenciando racionalmente os bens públicos, além da gestão adequada de resíduos sólidos e não esquecendo de cumprir sua missão colaborando para ampliar o acesso à informação, incentivar a leitura e práticas sustentáveis. (Cardoso, 2015:30.)

Analisando o caso da BVL, por tratar-se de um prédio adaptado para abrigar uma biblioteca localizada em um parque, que contempla diferentes espaços e propõe diversas atividades, é essencial que a estrutura siga a legislação e dialogue com a comunidade e com todo o seu entorno. De acordo com a proposta de Miller, mencionada na obra de Cardoso (2015: 30), para uma biblioteca tornar-se verde são necessárias algumas ações, que, adaptadas à realidade brasileira, podem ser divididas em quatro passos: plano de ação, projeto arquitetônico, serviços e educação ambiental. Importante notar que a sustentabilidade está ligada a várias questões e presente em vários aspectos - estrutural, educativo ou social. Geraldo e Pinto (2020: 132-133) apontam que, para receber o título de biblioteca verde, a Federação Internacional de Associações e Instituições Bibliotecárias (IFLA) informa que as instituições precisam 
criar consciência da responsabilidade social e liderança das bibliotecas em educação ambiental; apoiar o movimento mundial da Biblioteca Verde, preocupado com edifícios ambientalmente sustentáveis, recursos de informação ambientalmente sustentáveis e programação e conservação de recursos e energia; promover o desenvolvimento de iniciativas sustentáveis em nível local e mundial; e incentivar e apresentar ativamente suas atividades a uma audiência internacional.

Independentemente de ter ou não o título verde, a responsabilidade de implementar a Agenda 2030 é condição sine qua non para a biblioteca fazer a diferença e, com isso, "auxiliar seus usuários a compreender a importância do desenvolvimento sustentável no contexto atual e para as gerações futuras" (Geraldo e Pinto, 2020: 138). Weber (2012: 493) afirma que, "ao pensarmos a biblioteca como um organismo vivo, dinâmico e crescente, é possível pensá-la como alicerçada nas diretrizes que norteiam a sustentabilidade".

Logo, Weber (2012: 494) defende que, "ao relacionar o homem e ambiente, não podemos deixar de fundamentar um ponto essencial que é a aprendizagem ao longo da vida". Assim, pode-se dizer que as bibliotecas são o apoio essencial, tanto de aprendizagem quanto de desenvolvimento pessoal e independente. "Cada biblioteca possui um contexto, um público, uma natureza e serviços de informação condizentes com sua missão, mas todas possuem um compromisso social, especialmente a biblioteca pública" (Corrêa, Sá e Sobral, 2019:5).

Os ODS são um apelo universal à ação para acabar com a pobreza, reduzir a desigualdade, proteger o planeta e garantir que todos desfrutem a paz e a prosperidade. A Agenda 2030 reúne um conjunto de 17 objetivos, e a SP Leituras, que gere a BVL, também está fazendo sua parte. ${ }^{2}$ Conforme a Tabela 1, podemos observar os ODS trabalhados pela BVL.

Por meio de programas e projetos como os expostos na Tabela 1, as bibliotecas podem contribuir com a educação, mediante ações que possibilitem a conscientização dos usuários sobre a importância da sustentabilidade ambiental. Para Geraldo e Pinto (2020: 129), "as organizações [...] devem estabelecer um planejamento de metas e ações, buscando apresentar diretrizes que contemplam os ODS, beneficiando [...] meio ambiente, a humanidade e as gerações futuras", comprometidas e envolvidas com as questões sustentáveis. Dessa forma, a biblioteca deve estar pautada nos três pilares da sustentabilidade - o ambiental, o econômico e o social -, sendo possível obter melhores resultados dessas práticas a curto e a longo prazo.

2 Esses objetivos foram analisados em consonância com os programas e serviços desenvolvidos ou em desenvolvimento, divulgados pela própria biblioteca em seu site institucional. 


\begin{tabular}{|c|c|c|}
\hline & Agenda 2030 & $\begin{array}{c}\text { Programas e projetos da } \\
\text { Biblioteca Parque Villa-Lobos }\end{array}$ \\
\hline 1 ERRADICACAO & $\begin{array}{l}\text { Acabar com a pobreza em todas } \\
\text { as suas formas, em todos os } \\
\text { seus lugares }\end{array}$ & $\begin{array}{l}\text { Tecnologia dia a dia; Curso de } \\
\text { Libras; Oficina Espalhafatos de } \\
\text { Texto; Curso de Contação de } \\
\text { Histórias; oficinas voltadas à } \\
\text { cultura maker; empreendedo- } \\
\text { rismo; Agenda Cidadã; acesso } \\
\text { a computadores, internet e rede } \\
\text { Wi-Fi }\end{array}$ \\
\hline 3 SAGDEE & $\begin{array}{l}\text { Assegurar a vida saudável e } \\
\text { promover o bem-estar para } \\
\text { todos, em todas as idades }\end{array}$ & $\begin{array}{l}\text { Tecnologia dia a dia; Jogos para } \\
\text { Todos; loga; Oficina de Xadrez; } \\
\text { Sarau; Virada Sustentável; } \\
\text { Agenda Cidadã }\end{array}$ \\
\hline $4 \mathrm{EDU}$ & $\begin{array}{l}\text { Assegurar a educação inclusiva } \\
\text { e equitativa e de qualidade, e } \\
\text { promover as oportunidades de } \\
\text { aprendizagem ao longo da vida } \\
\text { para todos }\end{array}$ & $\begin{array}{l}\text { Hora do Conto; Brincando e } \\
\text { Aprendendo; Pintando o Sete; Lê } \\
\text { no Ninho; Luau; Clube de Leitu- } \\
\text { ra; Segundas intenções; Tecno- } \\
\text { logia dia a dia; Jogos Sensoriais; } \\
\text { Jogos para Todos; Leitura ao Pé } \\
\text { do Ouvido; Domingo no Parque; } \\
\text { Curso de Libras; Curso de Litera- } \\
\text { tura para Vestibular; Oficina de } \\
\text { Xadrez; Sarau; oficinas voltadas } \\
\text { à cultura maker; empreendedo- } \\
\text { rismo; Agenda Cidadã; Ponto } \\
\text { MIS; Programa Extramuros à Co- } \\
\text { munidade Jaguaré; Atendimento } \\
\text { Pró-Ativo; visitas monitoradas; } \\
\text { visitas técnicas; Pesquisa do } \\
\text { Instituto Fonte; capacitação da } \\
\text { equipe de atendimento; práticas } \\
\text { da BVL }\end{array}$ \\
\hline 6 AgUAPOIAVEI & $\begin{array}{l}\text { Assegurar a disponibilidade e } \\
\text { gestão sustentável da água e } \\
\text { saneamento para todos }\end{array}$ & $\begin{array}{l}\text { Virada Sustentável; utilização de } \\
\text { água de reuso }\end{array}$ \\
\hline 7 gagerialian & $\begin{array}{l}\text { Assegurar o acesso confiável, } \\
\text { sustentável, moderno e a preço } \\
\text { acessível à energia para todos }\end{array}$ & Virada Sustentável \\
\hline
\end{tabular}




\begin{tabular}{|c|c|c|}
\hline 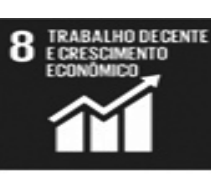 & $\begin{array}{l}\text { Promover o crescimento } \\
\text { econômico sustentado, inclusivo } \\
\text { e sustentável, emprego pleno } \\
\text { e produtivo e trabalho decente } \\
\text { para todos }\end{array}$ & $\begin{array}{l}\text { Empreendedorismo; Agenda } \\
\text { Cidadã; acesso a computadores, } \\
\text { internet e rede Wi-Fi }\end{array}$ \\
\hline 9 EDOSTIFA INOVACAO & $\begin{array}{l}\text { Construir infraestruturas resi- } \\
\text { lientes, promover a industriali- } \\
\text { zação inclusiva e sustentável e } \\
\text { fomentar a inovação }\end{array}$ & $\begin{array}{l}\text { Oficinas voltadas à cultura } \\
\text { maker; acesso a computadores, } \\
\text { internet e rede Wi-Fi }\end{array}$ \\
\hline AD & $\begin{array}{l}\text { Reduzir a desigualdade nos } \\
\text { países e entre eles }\end{array}$ & $\begin{array}{l}\text { Programa Extramuros à Comu- } \\
\text { nidade Jaguaré; acolhimento; } \\
\text { visitas de levantamento do } \\
\text { território }\end{array}$ \\
\hline 期洼罒 & $\begin{array}{l}\text { Tornar as cidades e os assenta- } \\
\text { mentos humanos inclusivos, se- } \\
\text { guros, resilientes e sustentáveis }\end{array}$ & $\begin{array}{l}\text { Programa Extramuros à } \\
\text { Comunidade Jaguaré; visitas de } \\
\text { levantamento do território }\end{array}$ \\
\hline 16 裁 & $\begin{array}{l}\text { Promover sociedades pacíficas } \\
\text { e inclusivas para o desenvolvi- } \\
\text { mento sustentável, proporcionar } \\
\text { o acesso à justiça para todos e } \\
\text { construir instituições eficazes, } \\
\text { responsáveis e inclusivas em } \\
\text { todos os níveis }\end{array}$ & $\begin{array}{l}\text { Agenda Cidadã; Área de Serviço } \\
\text { Social }\end{array}$ \\
\hline
\end{tabular}

Tabela 1. Objetivos da Agenda 2030 e ações da Biblioteca Parque Villa-Lobos (BVL)

Fonte: IFLA (2016) e SP Leituras (2018)

\section{Considerações Finais}

De acordo com a IFLA e a Federação Brasileira de Associações de Bibliotecários, Cientistas da Informação e Instituições (IFLA, 2016), as bibliotecas, ao promoverem ações que contribuem com os ODS da Agenda 2030, estão também propondo o advocacy entre si, ou seja, identificando, adotando e promovendo uma causa. Nesse sentido, é possível identificar de que maneira a BVL coloca em prática as ações relacionadas ao tema e vem trabalhando. Destaca-se que a grade de programação permanente da BVL vislumbra uma diversidade de atividades, as quais são divididas em grupos: crianças, jovens, adultos e pessoas com deficiência.

No que diz respeito ao ODS 1, Erradicação da pobreza, a biblioteca oferece, por intermédio de cursos de curta duração, oficinas e uso das tecnologias, 
subsídios para adquirir novas habilidades necessárias que possam contribuir para a educação e o emprego, assim como ao disponibilizar computadores e internet propicia, igualmente, o acesso à informação e a recursos que geram oportunidades para melhorar a vida das pessoas.

No que se refere ao ODS 3, Saúde e bem-estar, o acesso público à informação sobre saúde e bem-estar permite contribuir com as pessoas e famílias. A BVL, nesse intuito, propõe o uso da tecnologia, promove jogos, oficinas, ioga e eventos na área. Já o ODS 4, Educação de qualidade, considera que, pela capacitação e dedicação da equipe, é possível realizar atendimento diferenciado a crianças, jovens, adultos e pessoas com deficiência. $\mathrm{O}$ incentivo à educação na biblioteca se dá mediante programas como A Hora do Conto, Lê no Ninho, Clube da Leitura, entre outros. A BVL possibilita o acesso à informação e à pesquisa para estudantes, dispõe de espaços inclusivos e acessíveis para adquirir novos conhecimentos e habilidades, por intermédio de cursos, oficinas e do uso das tecnologias.

Os ODS 6 e 7 tratam, respectivamente, de Água potável e saneamento, e Energia limpa e acessível. Assim, atitudes como a utilização de água de reúso na BVL permitem que boas práticas façam parte da rotina e do despertar de consciência e desenvolvimento de projetos locais, além de possibilitar aos usuários partilhar de eventos em prol da sustentabilidade. O ODS 8, Trabalho decente e crescimento econômico, por sua vez, destaca-se na biblioteca pela promoção do acesso à informação e à capacitação para desenvolver habilidades de que as pessoas necessitam para encontrar melhores postos de trabalho, candidatar-se a eles e ter sucesso no mercado de trabalho.

Indústria, inovação e infraestrutura são previstas no ODS 9, e percebe-se a ampla estrutura oferecida pela biblioteca, com espaços agradáveis, inclusivos e acessíveis. Ganham destaque também os profissionais que atuam na biblioteca, pelo seu comprometimento e nível de qualificação promovido pela própria organização social que administra a biblioteca. Quanto ao ODS 10, que trata da Redução das desigualdades, a BVL com os seus espaços de aprendizagem procura desenvolver o acolhimento e acesso equitativo a todos. O ODS 11 remete-se às Cidades e comunidades sustentáveis, instituições confiáveis dedicadas a promover a inclusão e o intercâmbio cultural e a documentação e conservação do patrimônio cultural para as futuras gerações. Aqui a biblioteca vai ao encontro da comunidade, promovendo programas em diversos espaços, levando as práticas de mediação até as pessoas que não podem frequentá-las e contribuindo com o processo de formação e desenvolvimento humano.

Já o ODS 16 diz respeito à Paz, justiça e instituições eficazes, espaços inclusivos e politicamente neutros para que as pessoas possam reunir-se e 
organizar-se, bem como ter acesso público a informações. Nesse ponto, a BVL, em parceria com a Secretaria de Estado da Cultura, oferece a todos os sócios o Guia de Referência de Ofertas e Serviços, conhecido como Agenda Cidadã. Está disponível em todos os computadores da biblioteca, e o projeto reúne importantes sites que esclarecem como e onde ter acesso a serviços de assistência social, diversão e inclusão digital. O conteúdo é prestado por entes governamentais (das esferas federal, estadual e municipal), por empresas privadas e pelo terceiro setor (organizações não governamentais e organizações sociais). Ao promover esse trabalho, a BVL cumpre seu papel de agente de transformação social ao alinhar e integrar os interesses da comunidade com o acesso à informação de qualidade (BVL, 2018).

Pela excelência e qualidade de suas ações, foi possível identificar que a BVL se destaca como um lugar singular para o público. Quanto à parte estrutural, até o momento não possui nenhum tipo de certificação sustentável, no entanto a biblioteca aborda o tema da sustentabilidade em suas atividades e programas e vem conquistando o reconhecimento de sua atuação.

Por fim, ao visitar a BVL, podem-se constatar a magnitude e a beleza do local e conhecer um pouco melhor os espaços e alguns dos projetos promovidos. Estar no ambiente e ter informações de referência do local fizeram todo o sentido para esta pesquisa, possibilitando melhor compreensão dos documentos de referência e de percepção do modelo parque implantado no Brasil.

É oportuno expor que um projeto tão bem-sucedido quanto o da BVL, que contempla ações de incentivo à leitura, acessibilidade, sustentabilidade, cultura, informação e convivência, ultrapasse os seus limites e promova novas perspectivas nas vidas da população mais necessitada.

\section{REFERÊNCIAS}

Barilon, Adriana Azenha, Rosângela Formentini Caldas e Giulia de Sousa Ferrazoli. 2018. "Políticas culturais para bibliotecas públicas no Estado de São Paulo: análise dos investimentos culturais”. Múltiplos Olhares em Ciência da Informação 8 (2): 1-15. https://periodicos.ufmg.br/index.php/moci/article/view/16893

BVL (Biblioteca Parque Villa-Lobos). 2018. "Programas permanentes”. Acesso 17 jun. 2020. https://bvl.org.br/programas/

Cardoso, Nathalice Bezerra. 2015. "Bibliotecas verdes e sustentáveis no Brasil: diretrizes para bibliotecas públicas”. Tese de mestrado, Universidade Federal do Estado do Rio de Janeiro, Mestrado Profissional em Biblioteconomia. 
Corrêa, Nathália dos Santos, Maria Irene da Fonseca e Sá e Fabrícia Carla Ferreira Sobral. 2019. "A evolução das bibliotecas na sustentabilidade ambiental: uma análise comparativa de casos da América Latina”. Trabalho apresentado no IX Encuentro Ibérico EDICIC, Barcelona, 9-11 de julho. http://eprints.rclis.org/34436/

Freitas, Marília Augusta de e Vanessa Barbosa da Silva. 2014. "Bibliotecas públicas brasileiras: panorama e perspectivas”. Revista Digital de Biblioteconomia e Ciência da Informação 12 (1): 123-146. https://doi.org/10.20396/rdbci.v12i1.1621

Geraldo, Genilson e Marli Dias de Souza Pinto. 2020. "Marketing verde: propostas de atitudes sustentáveis em bibliotecas”. Informação@Profissões 9 (1): 124-142. https://doi.org/10.5433/2317-4390.2020v9n1p124

IBGE (Instituto Brasileiro de Geografia e Estatística). 2019. Sistema de Informações e Indicadores Culturais: 2007-2018. Rio de Janeiro: IBGE.

IFLA (Federação Internacional de Associações e Instituições Bibliotecárias/Federação Brasileira de Associações de Bibliotecários, Cientistas da Informação e Instituições (FEBAB)). 2016. "As bibliotecas podem promover a implementação da Agenda 2030”. Acesso 30 maio 2020. https:/www.ifla.org/files/assets/hq/topics/libraries-development/documents/ sdgs-insert-pt.pdf

Lima, Clovis Ricardo Montenegro de e Fátima Santana Silva. 2017. "A ética dos bibliotecários e a administração discursiva das bibliotecas orientada ao desenvolvimento sustentável", em Anais do Congresso Brasileiro de Biblioteconomia, Documentação e Ciência da Informação 27. Fortaleza: FEBAB. https://www.portal.febab.org.br/anais/issue/view/12/showToc

Medeiros, Ana Lígia. 2010. "Biblioteca e cidadania”. Sinais Sociais 14 (13): 10-45. Acesso em: 20 mar 2020. http://rubi.casaruibarbosa.gov.br/bitstream/20.500.11997/682/1/MEDEIROS\%2C\%20A.\%20L.\%20-\%20Biblioteca\%20e\%20cidadania\%20-\%20Sinais $\% 20$ sociais.pdf

Medeiros, Ana Lígia Silva. 2012. "Biblioteca pública no século XXI". CRB-8 Digital 5 (2): 49-55. http://hdl.handle.net/20.500.11959/brapci/10067

Medeiros, Ana Ligia Silva e Gilda Olinto. 2016. "As políticas públicas na área de bibliotecas públicas brasileiras”. Trabalho apresentado em Encontro Nacional de Pesquisa em Ciência da Informação, Brasil, 20-25 de novembro.

Silva, Aline Gonçalves da. 2012. "A biblioteca pública como fator de inclusão social e digital: um estudo da Biblioteca Parque de Manguinhos”. Tese de Mestrado, Universidade Federal do Rio de Janeiro, Mestrado em Ciência da Informação.

SisEB (Sistema Estadual de Bibliotecas do Estado de São Paulo). 2020. "Bibliotecas paulistas". Acesso 14 jun. 2020.

http://siseb.sp.gov.br/bibliotecas-paulistas/\#bibliotecas-estaduais

SNBP (Sistema Nacional de Bibliotecas Públicas). 2015. "Informações das bibliotecas públicas: dados 2015”. Acesso 5 jun. 2020.

http://snbp.cultura.gov.br/bibliotecaspublicas/

SNBP. 2020. “Sobre o SNBP”. Acesso 5 jun. 2020.

http://snbp.cultura.gov.br/sobre/ 
SP Leituras. 2018. "Dia de Ação Global da ONU: nós estamos fazendo nossa parte! E você?”. Acesso 15 jun. 2020.

https://bvl.org.br/dia-da-acao-global-da-onu-nos-estamos-fazendo-nossa-partee-voce/\#prettyPhoto

Spudeit, Daniela e Jorge Moisés Kroll do Prado. 2017. "Bibliotecas Parque e a Agenda 2030: análise das atividades no Rio de Janeiro”. Revista Brasileira de Biblioteconomia e Documentação 13 (1): 138-152.

http://dx.doi.org/10.22478/ufpb.1981-0695.2018v13n1.40112

Suaiden, Emir José. 2018. "O papel da biblioteca pública na reconstrução da verdade”. Ciência da Informação 47 (2): 143-152.

http://revista.ibict.br/ciinf/article/view/4285

Weber, Claudiane. 2012. "As bibliotecas e o aporte para o desenvolvimento sustentável”. Responsabilidade e Reciprocidade 1 (1): 491-496.

https://reciprocidade.emnuvens.com.br/rr/article/view/64

Para citar este texto:

Raulino, Cleide Elis da Cruz e Roberta Barros Meira. 2021. "A circulação de um modelo verde no Brasil: a Biblioteca Parque Villa-Lobos". Investigación Bibliotecológica: archivonomía, bibliotecología e información 35 (88): 13-28.

http://dx.doi.org/10.22201/iibi.24488321xe.2021.88.58360 